\title{
Research of flow parameters in a blow off of a hydraulic installation
}

\author{
Mikhail Balzannikov ${ }^{1, *}$, Semyon Piyavsky ${ }^{1}$, and Andrey Kurmanayev ${ }^{1}$ \\ 1 Samara State Technical University, Institute of Architecture and Civil Engineering, \\ Molodogvardeyskaya str. 194, 443001 Samara, Russia
}

\begin{abstract}
The paper deals with conditions and parameters of water flow in a blowoff of a hydraulic installation and adjacent area of a discharge channel. The authors point out the significant impact of forms and geometric sizes of outlet structures, as well as stilling structures on the linkage parameters of outlet water flow. The article presents results of research of the impact of a baffle on the water flow in discharge outlet and outlet canal and shows a possibility of hydraulic conditions improvement in discharge canal due to water-diverting wall construction. The authors conclude that deletion of a water-diverting wall in an outlet section of discharge outlet should be proved by technical and economic estimation.
\end{abstract}

\section{Introduction}

Waste water facilities are always considered as a part of hydraulic engineering units, constructed at natural water flows. These constructions are used for water discharge into the tail bay in the high water period, and design water flow in low-flow period [1-4]. If hydraulic water system has energy application, then part of water consumption is transmitted into the tail bay and also through the water conducting conduit of hydraulic units [5-8]. Water sluice constructions should meet high-level requirements, concerning their work safety and specific water flow design. Besides, water flow facilities should provide fast termination of water pass in case of emergency situations or their threat, and provide favorable hydraulic conditions of water flow, including output area into discharge channel [9-13].

Analysis of the results of studies of hydraulic structures and their water flow facilities allows to conclude that hydraulic conditions of water flow in the outlet channel are mostly influenced by the kinematic characteristics of the water flow and the nature of the velocity distribution throughout the height of the outlet section of a water flow facility, which are in turn determined by the shape and geometric parameters of the outlet area of the conduit [14-18]. It should be noted that the values of bottom velocity flow and, consequently, the parameters (firstly, thickness) of anchoring the bottom of outlet channel and its construction expenses are dependent on the matching conditions of output flow and tail bay. Moreover, the flow matching conditions and the characteristics of the flow stream is greatly influenced by the presence and form of stilling structures that provide flow deviation [19]. All

* Corresponding author: sgasu@samgasu.ru 
mentioned conditions and parameters largely determine the design solutions in the justification of the constructions of these elements in hydropower facilities [20-22].

Thus, research of hydraulic conditions of output flow in blow off, that helped to work out the recommendations on selection of rational shapes and geometric dimensions of water outlet, is very important, relevant and has a significant economic application.

The research objective - is research of hydraulic conditions of flow in blow off of hydraulic structures and outlet channel.

The main tasks that are necessary to achieve are the following:

- select typical constructive solutions of a water-discharge facility for the research sake;

- development of a mathematical model of outlet facility and outlet channel;

- implementation of the mathematical model description of outlet facility;

- application of the methodology of conducting model research and the rationale for the experiment boundary conditions related to the developed model;

- conducting of design-basis experiment and obtaining kinematic parameters of the flow in the water outlet facility and the outlet channel;

- analysis of the obtained results;

- formulation of conclusions and elaboration of recommendations to improve the hydraulic conditions of flow in the outlet facility of hydraulic structures and outlet channel.

\section{Research of flow parameters in a blow off of a hydraulic installation}

Upstream blow offs, in which water from the reservoir flows via the penstock and further goes under the level of a tail bay, are mostly widespread in low- and medium-head water power development. Structurally, the discharge outlet should include a flared part of rectangular cross section. The flared shape is necessary for reduction of water flow speed at the outlet of the discharge channel, and the rectangular cross-sectional shape is most efficient for its location in the output zone of the plain gate of rectangular shape.

Baffles of various types and constructions are used in order to reduce the section length of outlet canal that undergoes significant water flow bottom velocity. Stilling baffles and wells are often used as baffling facilities. These elements are designed to reduce flow velocities in the bottom section of the outlet channel and its scoring action due to deflection of water jets of water flow to the surface in the outlet channel in a tail bay.

However, if the water conduit is used to divert water from hydraulic units, providing work not only in the turbine, but in the pump modes, such stilling facilities may significantly and negatively affect the hydraulic conditions of reverse flow and, consequently, reduce the energy output of the power unit. The authors suggested the outlet structure with a movable water-diverting wall to ensure good working conditions of the outlet facility in both modes of possible operation of the power plant [23]. This structure provides protection of bottom anchoring of outlet channel from destructing effect of the flow, discharged from the water conduit. At the same time, the water-diverting wall is able to automatically clean the bottom of the pit and thereby eliminate the obstacle for the incoming flow, working in the water pump mode. This design was applied in the main research, based on the mathematical model.

A mathematical model of the outlet facility is designed in the software "ANSYS". The walls of the water conduit as well as the water level in tail bay are modeled as high-velocity contrasts.

However, all the main geometric parameters of the model of the outlet facility and the depth of water in tail bay in the model varied significantly during the experiment. The length of the flaring section changed particularly from $1 \mathrm{H}$ to $7 \mathrm{H}$, where $\mathrm{H}-$ is the height of 
the pressure conduit in front of the output section. The incidence angle of the top in the flaring section site varied from $0^{0}$ to $40^{\circ}$. Removal of water-diverting wall from outlet section of the conduit ranged from $1 \mathrm{H}$ to $9 \mathrm{H}$. The water depth in the outlet channel was calculated in the range from $3 \mathrm{H}$ to $7 \mathrm{H}$. The incidence angle of water-diverting wall was from $0^{0}$ to $45^{0}$ in vertical axis. The flow velocity in a characteristic cross-section in the discharge outlet was taken to be equal to $4 \mathrm{~m} / \mathrm{s}$ for this experiment.

The studies of the mathematical model resulted in flow characteristics in the operational part of the outlet facility and the outlet channel of a hydraulic structure.

The following figures show the results of calculations of flow rates for the water outlet facilities in hydraulic structures at varying distances of water-diverting wall from outlet section exit of a water outlet. The deviation angle of the wall from a vertical plane remained constant $-15^{0}$.

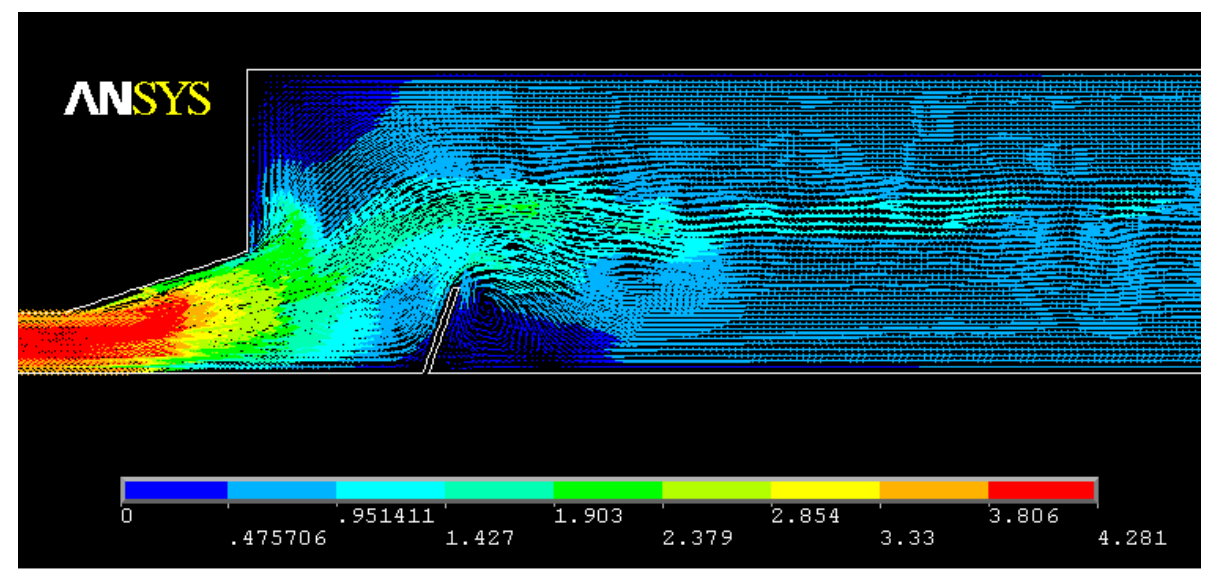

Fig. 1. The result of flow rates calculation in the process of removing water-diverting wall from outlet section equal to $3 \mathrm{H}$.

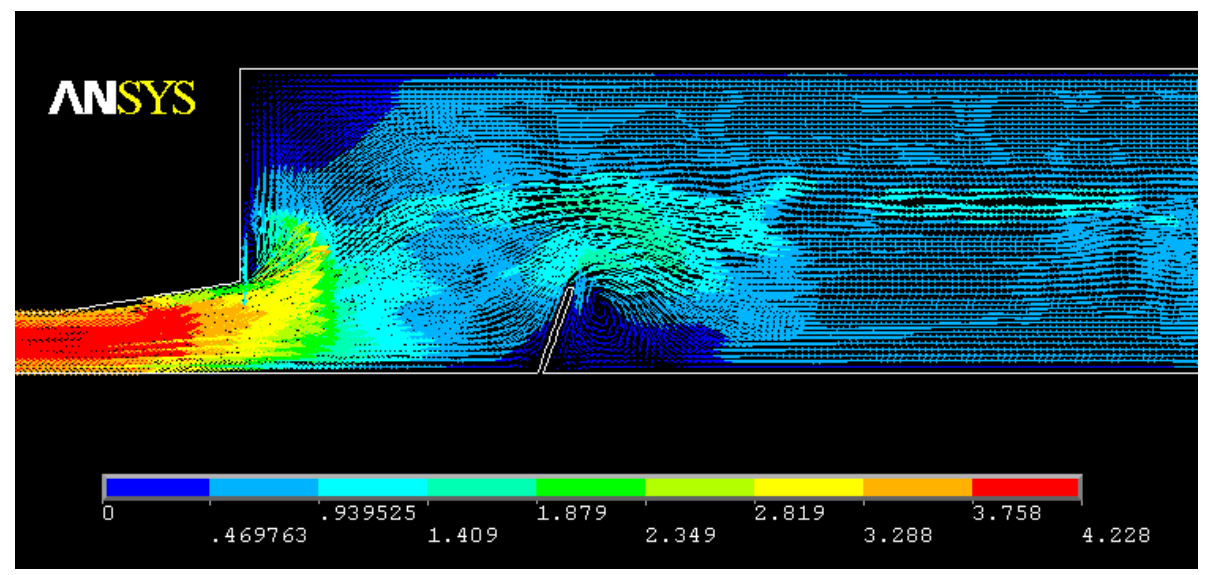

Fig. 2. The result of flow rates calculation in the process of removing water-diverting wall from outlet section equal to $5 \mathrm{H}$. 


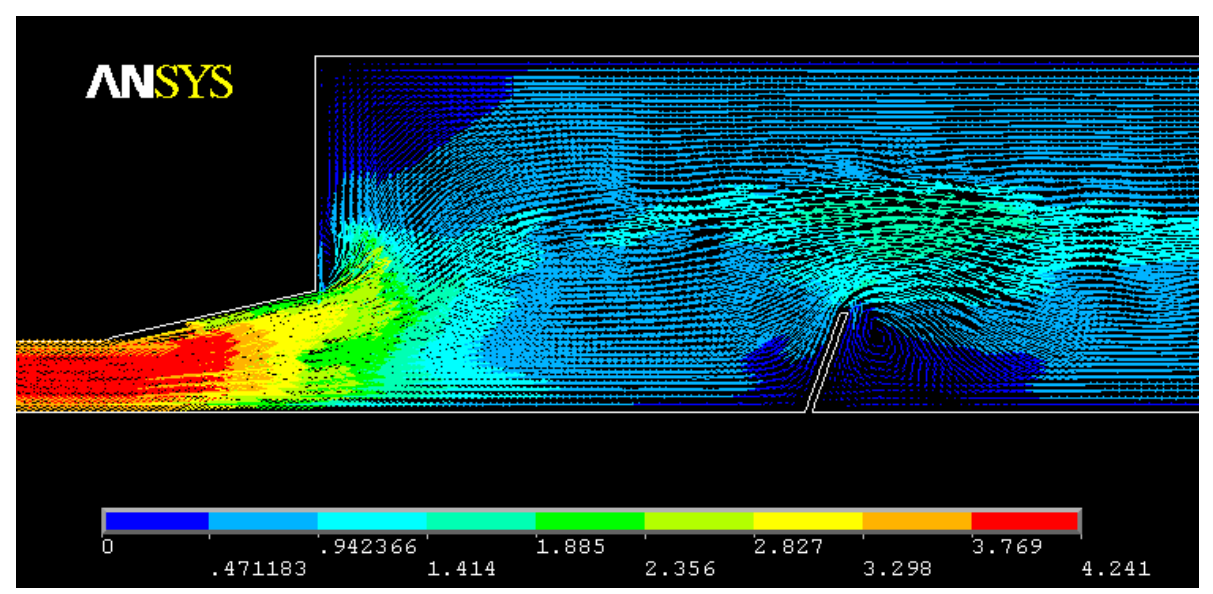

Fig. 3. The result of flow rates calculation in the process of removing water-diverting wall from outlet section equal to $7 \mathrm{H}$.

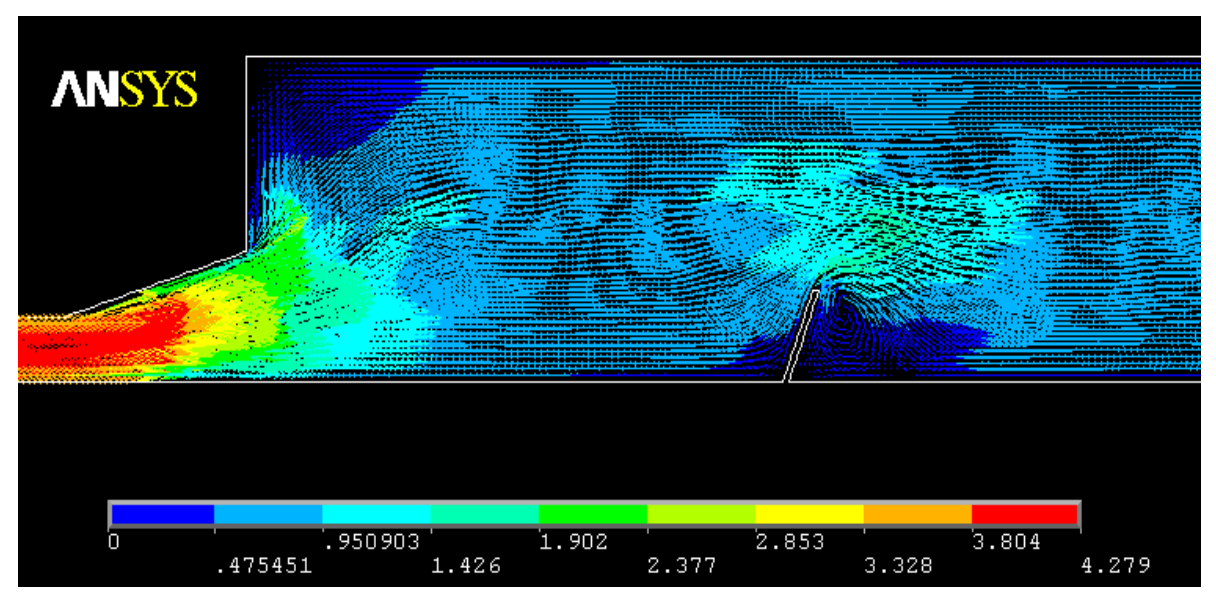

Fig. 4. The result of flow rates calculation in the process of removing water-diverting wall from outlet section equal to $9 \mathrm{H}$.

The results of the study show that the flaring section of an outlet facility in all considered variants plays a significant role in ensuring the reduction of velocity of water flow in the outlet section. The average speed in this area decreases from $4.0 \mathrm{~m} / \mathrm{s}$ to $2.0-3.0$ $\mathrm{m} / \mathrm{s}$ depending on the length of the section and the angle of incidence of the ceiling.

Then, after the flaring section, the flow goes to the outlet channel in the form of volatile widening transitional jet. Stagnant and whirling zones are clearly observed throughout the height of the discharge channel: at the top near the outlet section and in the bottom areas in front of a water-diverting wall and behind it.

The parameters (location and size) of the first stagnation zone for the considered variants do not differ from each other. The parameters of the stagnant zone in front of water-diverting wall change. In particular, the closer the wall is to the output section, the smaller size is formed in front of its area with small flow rates. However, the water flow is more actively dropped out in the upper layers, i.e. the locus of the streamlines becomes highly curved. It is important to consider that a significant change of the velocity vector of the transit flow will lead to an increase of pressure loss, which is undesirable for power water conducting system. In all cases, water-diverting wall of the bottom flow rate is much 
less than in front of the wall. Their values vary from zero value (at the distance of 2.0-2.5 of parameter $\mathrm{H}$ ), up to $0.3-0.4 \mathrm{~m} / \mathrm{s}-$ at a greater distance.

\section{Conclusion}

Thus, the analysis of the results showed that the presence of water-diverting wall in the outlet channel of the water conduit has a significant impact on the velocity distribution coming out of the water flow on the depth. In particular, a zone with very low velocities of water flow emerge almost immediately behind such wall, which, in turn, will allow to avoid the facility of considerable thickness of the bottom (usually concrete) stilling and reduce the amount of expensive material which will be beneficial from economic point of view.

The following two opposing trends should be considered in the process of designing location of a water-diverting wall.

On the one hand, fitting water-diverting wall to the outlet section of the conduit will reduce the length of the required solid concrete for mounting the bottom channel and bring down lump-sum costs (this is a positive effect). On the other hand, this solution will require strengthening of bearing elements of the used wall for increasing the pressure of the water flow and will increase the head losses due to the worsening of hydraulic conditions of the output flow (kinematics). The second factor will cause the need to increase non-recurring costs (cost of the wall) and other operational losses. Finally the location of water-diverting wall should be designed after conducting economic and technical research of possible options and identify the best economic solution.

\section{References}

1. V.V. Elistratov, V.I. Maslikov, G.I. Sidorenko, Water engineering 11, 11-15 (2014)

2. M.I. Balzannikov, V.M. Yurov, A.A. Mikhasek, Scientific survey 3, 101-108 (2015)

3. F. Switala, S.V. Evdokimov, Yu.M. Galitskova, Industrial and civil engineering 12, 87$90(2014)$

4. M.I. Balzannikov, M.V. Rodionov, V.A. Seliverstov, Vestnik SGASU. Town planning and architecture 1, 100-105 (2011)

5. M. I. Balzannikov, Vestnik SGASU. Town planning and architecture 4, 86-92 (2015)

6. Y.S. Vasiliyev, V.V. Elistratov, Hydropower installation (Publishing house of St. Petersburg state polytechnical university, Saint Petersburg, 2011)

7. M.I. Balzannikov, V.M.Yurov, A.A. Mikhasek, Procedia Engineering 111, 82-88 (2015)

8. Y. S.Vasiliyev, G. I.Sidorenko, V. V. Frolov, Scientific-technical Bulletin of SaintPetersburg state polytechnic university 147-1, 76-84 (2012)

9. S.V. Evdokimov, Vestnik SGASU. Town planning and architecture 2(6), 68-72 (2012)

10. S.A. Piyavskiy, S.V. Evdokimov, Proceedings of higher educational institutions. Construction 6 (643), 36-42 (2012)

11. M.I. Bal'zannikov, V.A. Zubkov, N.V. Kondrat'eva, V.A. Khurtin, Power Technology and Engineering 4(47), 267-272 (2013)

12. M. I. Balzannikov, B.G. Ivanov, A.A. Mikhasek, MGSU Bulletin 7, 119-124 (2012)

13. S.V. Evdokimov, T.V. Dormidontova, Vestnik SGASU. Town planning and architecture 1(5), 64-68 (2012)

14. M.I. Bal'zannikov, V.V. Elistratov, Power Technology and Engineering 12(28), 720725 (1994)

15. V.V. Elistratov, I.G. Kudryasheva, Yu.A. Miroshnikov, Hydraulic engineering 11, $22-$ 27 (2014)

16. M.I. Balzannikov, V.A. Seliverstov, Industrial and civil engineering 8, 17-19 (2010) 
17. M.I. Bal'zannikov, V.A. Seliverstov, Power Technology and Engineering (Springer New York Consultants Bureau) 3(46), 210-214 (2012)

18. G. S. Konigh, N.V. Kasatkin, A.M. Weinstein, A.G. Shkuropat, Proceedings of allRussian research Institute of hydraulic engineering in honour of B. E. Vedeneeva 259, 3-10 (2010)

19. G. K. Deryugin, Proceedings of all-Russian research Institute of hydraulic engineering in honour of B. E. Vedeneeva 275, 10-23 (2015)

20. Y.S. Vasiliyev, L.I. Kubyshkin, Hydraulic engineering 7, 2-8 (2014)

21. M.I. Bal'zannikov, V.A. Seliverstov, Power Technology and Engineering 1(49), 22-26 (2015)

22. S.V. Evdokimov, Industrial engineering 8, 35-38 (2010)

23. M.I. Balzannikov, A.L. Kurmanaev, Eastern European Scientific Journal 2, 282-286 (2014) 